\title{
Pathophysiological and anatomical basis of lymphatic transit of cancer cells and role of the lymphatic system: a review of published literature
}

\author{
Emad Matanes, Walter H. Gotlieb \\ Division of Gynecologic Oncology, Segal Cancer Center, Lady Davis Institute of Research, Jewish General Hospital, McGill University, Montreal, \\ Canada \\ Contributions: (I) Conception and design: WH Gotlieb; (II) Administrative support: All authors; (III) Provision of study materials or patients: All \\ authors; (IV) Collection and assembly of data: All authors; (V) Data analysis and interpretation: All authors; (VI) Manuscript writing: All authors; (VII) \\ Final approval of manuscript: All authors. \\ Correspondence to: Walter H. Gotlieb, MD, PhD. Chief Department of Obstetrics \& Gynecology, McGill University Sir Mortimer B. Davis Jewish \\ General Hospital, 3755 Chemin de la Cote-Ste-Catherine, Montreal, QC, H3T 1E2, Canada. Email: walter.gotlieb@mcgill.ca.
}

\begin{abstract}
Cancer metastasis involves dissemination of malignant cells from the primary tumor, via local lymphatic vessels to gain access to systemic circulation, while evading the destruction by immune cells, followed by successful extravasation and initiation of malignant growth in the distant organ. Despite the obvious contribution of the lymphatic system to the metastatic spread of cancer, basic research regarding the mechanisms leading to tumor dissemination via lymphatic vessels has been limited for years. Recent identification of molecular growth factors of lymphangiogenesis have led to new advances in our understanding of the underlying mechanisms of tumor metastasis. These growth factors have enabled scientists to better identify peritumoral lymphatics and to visualize precisely the ingrowth of tumor cells into the lumen of lymphatic capillaries. Moreover, it has been shown that these molecular markers secreted from a primary tumor can induce lymphangiogenesis in close regional lymph nodes, even prior to tumor cells arrival, which may facilitate metastasis spread. Comprehensive research of the multiplex interactions between tumor cells, lymphatics and the immune system will be crucial to further enhance the development of therapeutic and prognostic approaches to cancer. This review presents the ontogeny and anatomy of the lymphatic vasculature, discuss the immunological, molecular and physiological control of lymphatic vessel function, and explore the contribution of the lymphatic system to the development of metastases.
\end{abstract}

Keywords: Lymph node metastasis; lymphangiogenesis; lymphatic vessels; lymphatic metastasis

Submitted Aug 18, 2020. Accepted for publication Dec 08, 2020.

doi: $10.21037 /$ cco-20-205

View this article at: http://dx.doi.org/10.21037/cco-20-205

\section{Introduction}

Cancer metastasis, the main cause of cancer mortality, involves the dissemination of malignant cells from the primary tumor, via local blood or lymphatic vessels (LVs) to gain access to systemic circulation, while evading the destruction by immune cells, followed by successful extravasation and initiation of malignant growth in the distant organ (Figure 1) (1). Numerous studies have shown that most epithelial cancers primarily develop metastatic growth by propagating via LVs to the draining lymph nodes (LNs) and then via the bloodstream to distant organs. This explains the correlation between the detection of metastases within the LNs and the prognosis, that is at the basis of many therapeutic decisions (2). Despite the obvious clinical relevance of LN metastasis and its impact on survival, the mechanism leading to tumor spread via LVs is the result of a very complex and controlled system, that has remained 


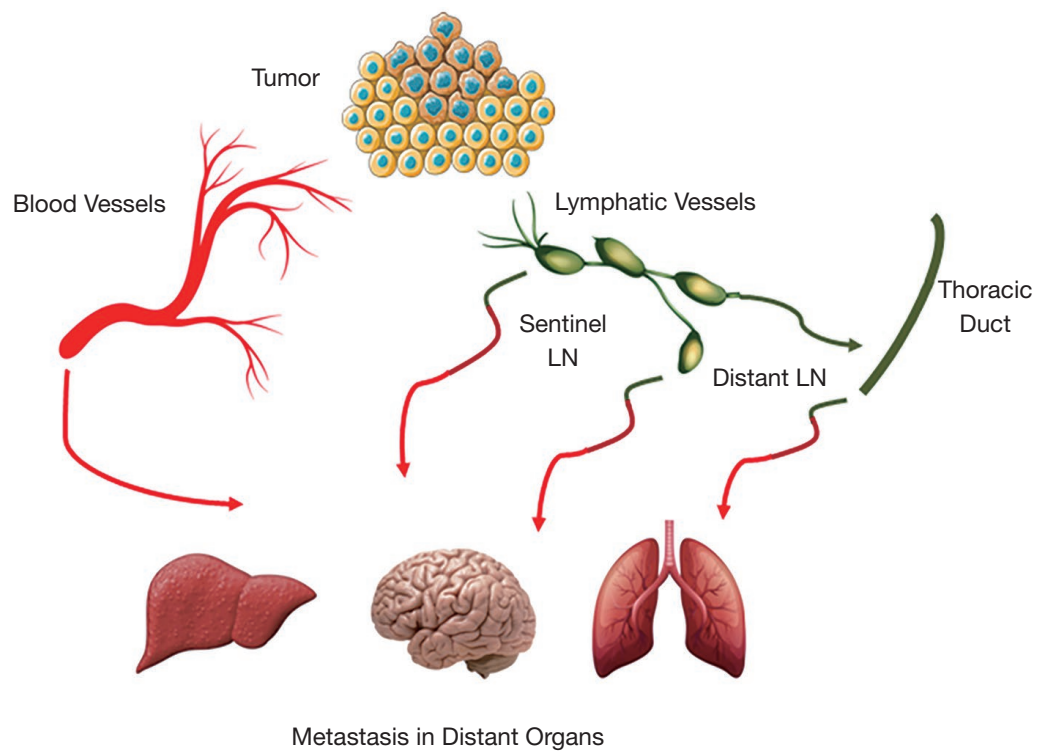

Figure 1 Current concepts of lymphatic and blood metastasis. Different pathways can result in cancer spread. Cancerous cells can invade the intra or peritumoral LVs and establish metastases in the nearby sentinel LN. Further metastatic dissemination occurs either from the sentinel LN to distant LN or through the thoracic duct to distant sites. Additionally, cancerous cells potentially spread through blood vessels with or without dropping by the sentinel LN to form metastases in distant organs.

mysterious for decades. Several factors lead to the limited comprehension of the importance of the lymphatic system in metastasis spread: (I) the paucity of molecular markers that reliably differentiate LVs from blood vasculature within and surrounding the primary lesion, (II) the shortage of suitable experimental models to study and quantify LN metastasis, (III) the limited scientific interest in LVs system as compared to blood vessels system. The structure, development, and function of the lymphatic vasculature has been the subject of extensive studies over the past two decades, fueled by detection of the primary lymphatic growth factors (3) and markers that help recognize LVs in tissue $(4,5)$. These seminal findings have allowed the investigation of the lymphangiogenesis in the embryo (4), the growth, maturation, and function of the lymphatic system in the adult (6), the role of lymphatics in malignancy development $(7,8)$ and this might ultimately lead to the identification of several molecules in the lymphangiogenic pathway as therapeutic targets (9). In this review, we aimed to explore the current understanding of the highly controlled and complex processes of the pathophysiology and the anatomical basis of the lymphatic system in normal and malignant processes.

\section{The importance of the tumor microenvironment in metastasis}

The genotypic and phenotypic make-up of a tumor is a major determinant of its metastatic potential, and a receptive microenvironment is necessary for successful tumor growth in the original cancer site and in the metastatic site $(10,11)$. In 1889, Stephen Paget was the first to report that metastatic dissemination of malignancy to various organs is not a random process. Paget evaluated data from 735 postmortem patients with breast cancer, and recognized that metastasis is not due to chance events and he proclaim the "seed and soil" theory: tumor cells (the "seed") grow preferentially in the microenvironment of selected organs (the "soil") and that metastases resulted only when the appropriate seed was implanted in its suitable soil (12). In the subsequent years, numerous studies has supported Paget's assertion that the tumor microenvironment has an essential impact on regulating the growth of metastases $(13,14)$. It has been shown that tumor invasion and metastatic dissemination are dependent on the cooperation of multiple congruent adhesion signals and molecular networks in the tissue. Cellular behavior and activation or inactivation of genes are influenced heavily by 
Table 1 Differences in metastatic dissemination of gynecologic cancers

\begin{tabular}{lll}
\hline Type of cancer & Subtypes & Loco-regional spread pattern \\
\hline $\begin{array}{l}\text { Vulvar, endometrial and cervical } \\
\text { cancers }\end{array}$ & $\begin{array}{l}\text { Arise typically from pre-malignant } \\
\text { lesions (18) }\end{array}$ & $\begin{array}{l}\text { Loco-regional dissemination occurs principally by local invasion } \\
\text { into the lymphatic system } \\
\text { Process is faster for some high risk subtypes (19) }\end{array}$ \\
"Ovarian" cancer* & High-grade serous subtype (15) & Originates in the fallopian tube \\
& Clear cell and low-grade & $\begin{array}{l}\text { Shed in the peritoneal cavity causing carcinomatosis (20) } \\
\text { Common precursor in the endometrium }\end{array}$
\end{tabular}
endometrioid

Up to $40 \%$ have somatic ARIDla mutations (21)

Low-grade serous ovarian cancers Appear to initiate in the normal surface epithelium of the ovary (22)

*, the ovary and the fallopian tube are "inside-out" organs, where the epithelium faces the peritoneal cavity. Shed malignant tubal cells find a welcoming "soil" on the vascular and dynamic ovarian surface $(20,23)$. The microenvironments of the abdominopelvic serosa, peritoneal mesothelium, and omentum are similarly favorable (16).

the local tumor microenvironment. This reinforces the idea that a complex interplay of molecules and signals is needed for metastasis development (11).

The microenvironment of the tumor sites has a high metabolic demand requiring adequate blood supply for nutrients, removal of waste, influx of immune and stromal cells, and ultimately as a conduit for lymph-hematogenous spread (15-17). Tumors have developed mechanisms to sustain themselves such as angiogenesis (the formation of new blood vessels), and lymphangiogenesis (the emergence of new lymphatic vessels from pre-existing lymphatics) (17).

Angio-regulatory factors are secreted by elements of the tumor microenvironment, leading to new vasculature that supports tumor survival and progression (16). Invasion, angiogenesis, lymphangiogenesis, and metastasis are thus controlled within the tumor microenvironment through a dynamic interaction between the tumor cells, the extracellular matrix (ECM), stromal and immune cells, and secreted chemokines and growth factors $(16,17)$.

Differences in metastatic dissemination of gynecologic cancers are listed in Table 1.

\section{The lymphatic system}

The lymphatic system is a network of LVs, lymphoid organs, and lymphoid tissues that assist the organism to get rid of toxins and undesired materials (24). The primary function of the lymphatic system is to transport lymph, a fluid containing immune cells, proteins and excess interstitial fluid, throughout the body (25). Although the lymphatic and blood vascular systems are structurally two different systems, they are functionally interconnected and act in harmony to maintain tissue homeostasis. The blood vasculature contains a basal membrane, pericytes surrounding the endothelial cells, and smooth muscle cells in larger vessels (26). On the other hand, the lymphatic system consists of the lymphoid organs such as spleen, thymus, LNs, bone marrow, and Peyer's patches that are connected by LVs (24). Unlike blood vessels, LVs are consisting of a single layer of lymphatic endothelial cells (LECs), which is not surrounded by a basement membrane, pericytes, or smooth muscle cells. Instead, these blinded ending vessels are lined with a single layer of overlapping endothelial cells that form loose intercellular junction. These lymphatic capillaries are highly permeable to migrating cell, macromolecules, and different pathogens (27).

The lymphatic system in numerous ways complements functions of the blood vascular system by enhancing interstitial protein transport, regulating tissue fluid balance, and implementing immunological functions. Generally, fluid and plasma proteins that leak out of the venules to the tissue, and can not be reabsorbed directly, are returned back into the circulation as an act of the large lymphatics. Lymph returns to the venous circulation through the thoracic duct draining into the subclavian vein. Lymphatic flow is driven mainly by arterial pulsations, contraction of smooth muscle cells lining the large collecting LVs, and the action of neighboring skeletal muscles (28) (Figure 2).

\section{Ontogeny of the lymph vessels}

Historically, two hypotheses have been proposed on the embryonic origins of lymphatic development: the first 


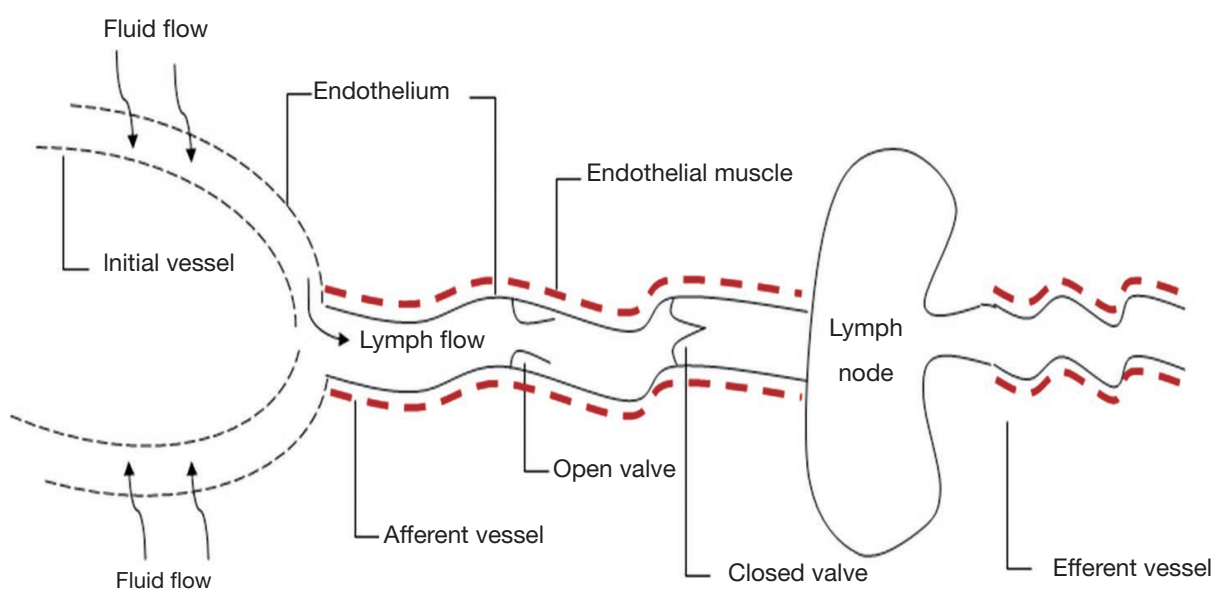

Figure 2 Anatomy of the lymphatic network. The lymphatic network is composed by initial LVs where the interstitial fluid is collected to create lymph, collecting afferent LVs which carry fluid to LN and efferent LVs which carry fluid out of the LN either to the next node in the chain or to the blood system. The collecting LVs are surrounded by a single layer of smooth endothelial muscle cells that contract to drive flow. Lymph backflow is prevented by intraluminal valves in the LVs.

based on lymphangioblasts, the second on embryonic veins. In the first model the primary lymphatics develop from specific precursor cells-lymphangioblasts, independently from veins, and only later linkage with the venous system is established (29). The alternative and most widely agreeable hypothesis is that the lymphatics develop from embryonic veins. This theory was proposed in 1902, by Florence Sabin (30) who speculated that the peripheral lymphatic system develops from the primary lymph sacs, originating from vascular endothelial cells, and then spreads by endothelial sprouting to form capillaries.

Minimal progress had been achieved since then, due to the paucity of molecular markers that reliably differentiate lymphatics from blood vasculature. A major breakthrough was the discovery of a lymphatic-specific marker in 1999, named the lymphatic vessel endothelial hyaluronan receptor 1 (LYVE1) (4). It provided a precise tool to specifically recognize LVs in a variety of tissues, leading to investigations of tumor-associated lymphatics $(31,32)$. Another step forward was the detection of the lymphangiogenic vascular endothelial growth factors VEGF-C and VEGF-D and later the discovery of their receptor VEGFR-3 $(32,33)$. Additionally, the identification of the membrane glycoprotein "podoplanin" (34) and the transcription factor prospero-related homeobox 1 (PROX1) (5) which are highly expressed by LVs but not blood vessels, and the discovery of an antibody that specifically detects human podoplanin (35), expedited robust research of LVs in the cancer field (Table 2).

Embryologically, lymphangiogenesis starts with the expression of Lyve-1 by lymphatic capillaries in venous endothelial cells of the cardinal vein (43), leading endothelial cells to become responsive to lymphatic signals such as Prox-1 (39), podoplanin (34) and VEGF-C $(44,45)$ (secreted mostly by immune cells such as macrophages, dendritic cells, and neutrophils), giving rise to the lymphatic vasculature. Remodeling and maturation of the initial LV network into lymphatic capillaries and collecting LVs, are mediated by multiple factors, such as the transcription factor forkhead box protein C2 (Foxc2) (46), the non-kinase receptor neuropilin-2 (47), the growth factor angiopoietin-2 (48), and the Eph receptor ligand ephrinB2 (49). This process requires the growth of new lymphatic capillaries from preexisting ones, the acquisition of mural cell coverage, and the development of valves within collecting LVs walls.

\section{Lymphatic metastasis}

LVs represent the routes for trafficking through the body of reabsorbed immune cells, but malignant cells are exploiting these routes to travel via to the nearby sentinel LN, regional distal LN, and then to distant organs (1). The extent of LN involvement is a key prognostic factor for the outcome of the disease and often guides therapeutic decisions (50).

Lymphatic metastasis, historically thought to be a passive process, is now known to be a highly regulated process at 
Table 2 Essential discoveries in lymphatic vessel development and molecular markers that facilitate differentiating between blood and lymphatic vessels

\begin{tabular}{llcc}
\hline Marker/Factor & Function & Year & Reference \\
\hline VEGF-C- VEGF-D & $\begin{array}{l}\text { Stimulates both, VEGFR-2 and VEGFR-3, leading to angiogenesis and } \\
\text { lymphangiogenesis }\end{array}$ & 1996 & Paavonen (36) \\
LYVE-1 & Modulates the transport of hyaluronan by LECs & 1999 & Baneji (4) \\
LyP-1, Nrp2 & Coreceptors for VEGF-C in lymphatic vessels & 2002 & Laakkonen (37) \\
& & Alitalo (38) \\
PROX-1 & Essential for embryonic lymphatic development & 2002 Wigle (39) \\
PODOPLANIN & Co-expressed with VEGFR-3 in initial lymphatic vessels & 1999 & Breiteneder-Geleff (34) \\
COX-2 & Enhances the expression of sema7a leading to the activation of $\beta 1$-integrin & 2016 & Black (40) \\
TNF- $\alpha$ & receptors leading to increased lymphangiogenesis & 2002 & Ji (41) \\
CCL19 and CCL21 & Modulates migration of dendritic cells to the regional LNs & 1998 & Baggiolini (42) \\
\hline
\end{tabular}

different levels, including the movement of cancerous cells towards LVs and the efficient penetration to the lymph system (51).

Most malignant epithelial tumors are surrounded by peritumoral lymphatics (52). The hydrostatic pressure differences following the cancer cells invasion to the ECM, result in fluid flow that transport cells to the peritumoral lymphatic capillaries. Cancer cells invasion, motility surrounded by ECM, and movement toward the lymphatic capillaries are driven by several factors including proteolytic enzymes' secretion, expression of adhesion receptors, and chemokinesis (17). Upon tumor cells arrival to the adjacent lymphatic capillaries, fine cytoplasmic processes mobilize the cancer cells along the external surface of the endothelium. Cells' migration toward the lymphatics and invasion into the lumen are carried out either by inducing the opening of closed gaps or through open interendothelial gaps (19,53).

Intra-tumoral interstitial fluid pressure increases as tumors grow in size $(19,50,54)$, leading to lymph flow to be in the direction of the peritumoral lymphatics, resulting in an increase in the volume of the interstitial fluid. Once access to the lymphatic lumen is gained, smooth muscles in the walls of the lymphatic vessels pump lymph rhythmically, with the assistance of the placed valves that prevent backflow $(19,55)$, leading the cancer cells to embolize alone or in clusters to the sentinel LNs (Figure 2). Through afferent lymphatics, tumor cells pass the subcapsular sinus of the $\mathrm{LN}$ and then either cells pervade into the cortex of the node, bypass it via lymphatic-venous connections (56), or bypass the node completely and progress directly into the efferent lymphatics to the next LNs $(57,58)$.

\section{Patterns of lymphatic metastasis}

Apparently, the "seed" and the "soil" process is likely determined by several factors including molecular alterations within the tumor microenvironment, acquired mutations promoting invasion, molecular interplay between tumor cells and blood and lymphatic vasculature and ultimately the anatomical and molecular characteristics of the target tissue $(19,59,60)$. While direct hematogenous spread can possibly happen, the robust association between tumor lymphangiogenesis and distant metastasis formation favors a sequential model of metastasis evolution where tumor cells spread first to the lymphatic system and from there into blood system either directly or ultimately through the thoracic duct $(19,61)$ (Figure 2).

Brown et al. (62) recently confirmed this sequential model in mice. He showed that metastatic tumor cells migrate to the sentinel LNs and then disseminate to distant sites by gaining access to blood vasculature. Using genomic analyses to reconstruct clonal evolution of primary tumor and metastasis, from a single prostate cancer patient, Hong et al. (59) showed complex pattern of metastatic dissemination that include recolonization of the primary tumor and cross-colonization between different metastases. In melanoma, when the timing of metastatic 
seeding was examined in relation to tumor thickness and specific genomic alterations, it was shown that lymphatic involvement takes place shortly after the dermis is invaded by the primary tumor and that typical driver mutations can be acquired by tumor cells within the LN. Therefore, melanoma cells can leave primary tumors early and then grow in parallel at different sites such as the LN (63). Unlike early metastasis that may result in an independent simultaneously growth of the cancer in different locations, late metastasis may evolve in a more linear pattern and gradual acquisition of additional genetic mutations (59).

The metastatic spread through the LVs to regional LNs in many cancers is considered the first distant development beyond local advancement, and therefore represents an important sign of the metastatic potential of the tumor $(64,65)$. In some tumors such as colorectal cancers, $\mathrm{LN}$ dissection appears to have therapeutic value and provide overall survival benefit, and LN removal remains an important determinant for prognosis despite that most of these tumors spread directly to the liver via the venous system (66). The impact of lymphadenectomy on prognosis is still subject of debate in most cancers, including gynecologic cancers, failing to show any survival advantage of the removal of LNs (67).

\section{Molecular regulation of LN metastasis}

Numerous signaling molecules cooperate in the highly complex regulation of lymphangiogenesis $(3,68)$ (Table 2$)$.

(I) The first major family of signaling pathways that dominate the lymphatic endothelial cell biology is ANG-TIE (angiopoietin-tyrosine kinase with immunoglobulin and epidermal growth factor homology domain). Angiopoietin molecules have an essential role in stimulating postnatal vessel growth, remodeling, and maturation $(37,69)$.

(II) The second is the VEGF-VEGFR (vascular endothelial growth factor-VEGF receptor) family. VEGF-C (36) was the first growth factor that was found to induce lymphangiogenesis, in addition to its important role in angiogenesis (70,71). The "mature" form of VEGF-C activates VEGFR-2 as well as VEGFR-3, leading to angiogenesis and lymphangiogenesis, whereas the "immature" form preferentially binds and activates VEGFR-3 only, and specifically induces lymphangiogenesis (72). Structurally, VEGF-C resembles vascular endothelial growth factor-D (VEGF-D), which also binds to and stimulates VEGFR-2 and VEGFR-3 in a similar manner and induces angiogenesis and lymphangiogenesis $(33,73)$. VEGF- C expression has been reported in several studies to be correlated with metastatic spread to regional lymph nodes including in breast (74), colon (75), lung (76), and gynecologic malignancies (77-81).

(III) Another group of chemoattractant cytokines (CC) called "Chemokines" is involved in the lymphangiogenesis process. "Chemokines" is a family of more than $40 \mathrm{CC}$ that bind to G-protein-coupled receptors on target cells to enhance cytoskeletal rearrangement, firm adhesion to endothelial cells, and directional migration $(42,82)$. Chemokines have an important role in the regulation of both, physiologic and pathologic lymphocytic cell traffic (83). Chemokine ligand (CCL19) is secreted by dendritic cells. Majority of T-cells that present chemokine receptor 7 (CCR7) are responsive to CCL19 secretion and follow a gradient in its concentration. CCR7 receptor and its ligands CCL19 and CCL21 are crucial in the travel of dendritic cells to the regional LNs and when their interaction is blocked, dendritic cells fail to migrate (84).

(IV) Tumor necrosis factor-alpha (TNF $\alpha)$ is a cell signaling protein involved in systemic inflammation and is one of the cytokines that make up the immunologic acute phase reaction. It is produced mainly by activated macrophages (85). VEGF-C secretion by tumor-associated macrophages is triggered by the interaction between $\mathrm{TNF} \alpha$ and its TNF receptor 1 (TNFR-1), leading to amplification of lymphatics expansion and metastasis (41). Furthermore, TNF $\alpha$ induced lymphangiogenesis significantly relies on the VEGF-C/VEGFR3-induced LEC tip formation which is mandatory to activate fibroblast growth factor (FGF2) that stimulates lymphangiogenesis and promotes tumor metastasis (86). On the other hand, proangiogenic factors such as angiopoietins (87) and platelet derived growth factor B (88) serve as direct lymphaniogenic factors by binding to their specific receptors expressed by LECs.

(V) Cyclooxygenase-2 (COX-2) is an enzyme that is encoded by the prostaglandin-endoperoxide synthase 2 gene (89). It is involved in the conversion of arachidonic acid to prostaglandin $\mathrm{H} 2$, an important precursor of prostacyclin, which is expressed in inflammation. Black et al. has demonstrated 
Table 3 Immunomodulation by lymphatic epithelial cells (LEC)

\begin{tabular}{lll}
\hline Action & Mechanism & Outcome \\
\hline $\begin{array}{l}\text { Present exogenous antigens on MHC I without } \\
\text { costimulatory molecules }\end{array}$ & Inhibit T cell proliferation \& function & ${\text { Apoptosis of CD8 }{ }^{+} \text {T cells }}^{\text {Present endogenous tissue-restricted antigens on }}$ \\
MHC-I & Inhibit T cell proliferation \& function & Eliminates autoreactive CD8 ${ }^{+}$cells \\
Produce nitric oxide & & Inhibits T cells \\
ICAM-1 upregulation & Depletion of tryptophan & Inhibits dendritic cell maturation \\
IDO production & & Inhibits T cell proliferation \\
Release of S1P & & Egress of activated T cells from LN \\
& & Promotes survival of naïve T cells \\
\hline
\end{tabular}

LEC cells play an important role in many immunomodulatory functions (detailed description in text). MHC-I, major histocompatibility complex class I; ICAM-1, intercellular adhesion molecule 1; IDO, indoleamine 2,3-dioxygenase; S1P, sphingosine 1-phosphate.

recently the pro-lymphangiogenic effect of COX2 that stimulates semaphorin 7 a expression in breast cancerous cells resulting in activation of $\beta 1$ integrin receptors on adjacent cancerous cells and LECs, to eventually increase lymphangiogenesis and metastasis spread (40). Additionally, semaphorin 7a gene is highly expressed in breast cancer cells and correlates with poor prognosis and metastatic disease (40). Moreover, Elder et al. has shown that semaphorin 7 a stimulates gp 38 upregulation in breast cancer by tumor-infiltrating macrophages, and this leads to promote their adhesion to LVs and this leads to lymphangiogenesis induction and metastasis spread (90).

\section{Immune interactions in lymphatics}

LECs, the main components of lymphatics, undergo active modifications that promote metastatic spread during tumor development, and enhance immunoregulation. It has been shown that LECs which are found in the cancer microenvironment can serve as an immunoregulator of the T cell response against tumoral cells (91). To overcome the immune system defenses and enhance the metastatic potential, tumors express immunosuppressive ligands and recruit a variety of immunosuppressive leucocyte subtypes to the primary tumor site, sentinel $\mathrm{LN}$ and metastatic sites as well $(1,92)$. Recently, evading this immunosuppression is the principal rationale of several new immunotherapy approaches and holds promise for controlling established metastatic cancer $(92,93)$.
Lymphatics display either positive or negative effects on tumor immunity; on one hand lymphatics have been implicated in tumor immunosuppression, but there is also evidence that lymphatics have a role in the induction of anti-tumor immune responses.

Generally, LECs are critical for the transport of immune mediators from peripheral organs to LNs leading to the immune response initiation $(94,95)$. In addition to their role in tissue drainage and immune cell migration, LECs mediate $\mathrm{T}$ cell responses via various mechanisms (Table 3) (96):

(I) LECs can cross-present exogenous antigens on major histocompatibility complex class I (MHC I) in the presence of PD-L1, which signals through PD-1 to suppress the proliferation and function of the $\mathrm{T}$ cells leading to apoptosis of antigen-specific CD8+ T cells $(97,98)$.

(II) LECs play a role in peripheral $\mathrm{T}$ cell tolerance by exposing endogenously expressed tissue-restricted antigens (94) via MHC I molecules and discarding autoreactive $\mathrm{CD}^{+} \mathrm{T}$ cells $(98,99)$.

(III) $\mathrm{T}$ cell activation and proliferation in a negative regulatory feedback process can be prevented by LECs. This can be achieved by producing nitric oxide in response to inflammatory signals (Interferon $\gamma(\mathrm{IFN} \gamma$ ) and $\mathrm{TNF} \alpha$ ) secreted by $\mathrm{T}$ cells, resulting in T cell inhibition (100).

(IV) LECs, stimulated by IFN $\gamma$ and TNF $\alpha$, suppress dendritic cell maturation through ICAM-1 upregulation (101); suppress T cell proliferation via enzymatic depletion of tryptophan by indoleamine 
2,3-dioxygenase (IDO) (102); and also upregulate MHC II (103).

(V) The impact of LECs on peripheral CD4+ T cell responses in various immunological settings still debatable. LECs were shown in Rouhani et al. study to be unable to load MHCII molecules with antigenic peptides owing to their $\mathrm{H} 2-\mathrm{M}$ deficiency at steady-state (103). On the other hand, Dubrot et al. showed that surface MHCII could be expressed on LN stromal cells as a result of the combination of both acquired and endogenous molecules (104).

(VI) LECs, by releasing the sphingosine 1-phosphate (S1P), are essential in releasing of activated $\mathrm{T}$ cells from LNs (105) and maintaining naïve T cells (106).

Lymphatics can also enable anti-tumor immune responses $(107,108)$, as indicated by transgenic mice with defects in dermal lymphatic drainage, that displayed a defective immune responses to implanted cancerous cells (109).

High serum VEGF-C has been correlated with response to immunotherapy in melanoma patients and could be used as a biomarker for immunotherapy, despite its association with lymphatic metastasis (93), and VEGF-C resulted in an enhanced immune response against glioblastoma tumors (110). VEGF-C/VEGFR-3 signaling increased the number of activated $\mathrm{T}$ cells within primary melanoma lesions. In colorectal cancer decreased $\mathrm{LV}$ presence at the invasive margin of the specimen was associated with reduced infiltration of cytotoxic $T$ cells and both were correlated with higher rate of distant metastasis (111). Furthermore, serum VEGF-C levels in cancer patients was found to be positively correlated with immunotherapy responses and even with survival outcome (93). One will need to balance the value of anti-lymphangiogenesis therapy with the risk that it might affect the effectiveness of immunotherapy.

\section{Conclusions and future directions}

The role of the lymphatic system in cancer development is currently receiving extensive scientific and clinical interests; the identification of molecular lymphangiogenic factors and receptors and the implications of their activity in normal physiology and pathology have improved our comprehension of the underlying mechanisms of tumor metastasis. It is now clear that tumor lymphangiogenesis is crucial in tumor development and blocking this process might inhibit metastasis to LNs. Moreover, lymphatic vascular markers may be useful as a prognostic indicator of metastatic risk. Novel targets have been identified, supporting biologically based therapeutic opportunities, and one such lymphatic-targeted therapy is already being used to preclude corneal grafts rejection (7). Further knowledge in the area of lymphagiogenesis will enable researchers and clinicians to investigate and treat tumors in a targeted and efficient fashion, being careful not to interfere with antitumor immunity. Additionally, a molecular understanding of factors that predict the likelihood of $\mathrm{LN}$ metastasis, i.e., a molecular signature, could replace the need for regional lymph node sampling.

\section{Acknowledgments}

Funding: This study was supported by grants from the Israel Cancer Research Fund, the Gloria's Girls Fund, the Susan and Jonathan Wener Fund, and the Anne-Marie and Mitch Garber Fund.

\section{Footnote}

Provenance and Peer Review: This article was commissioned by the Guest Editors (Denis Querleu and Cherif Youssef Akladios) for the series "Sentinel Lymph Node Biopsy in Gynecologic Cancer" published in Chinese Clinical Oncology. The article was sent for external peer review organized by the Guest Editors and the editorial office.

Conflicts of Interest: Both authors have completed the ICMJE uniform disclosure form (available at http://dx.doi. org/10.21037/cco-20-205). The series "Sentinel Lymph Node Biopsy in Gynecologic Cancer" was commissioned by the editorial office without any funding or sponsorship. The authors have no other conflicts of interest to declare.

Ethical Statement: All authors are accountable for all aspects of the work in ensuring that questions related to the accuracy or integrity of any part of the work are appropriately investigated and resolved.

Open Access Statement: This is an Open Access article distributed in accordance with the Creative Commons Attribution-NonCommercial-NoDerivs 4.0 International License (CC BY-NC-ND 4.0), which permits the noncommercial replication and distribution of the article with the strict proviso that no changes or edits are made and the original work is properly cited (including links to both the 
formal publication through the relevant DOI and the license). See: https://creativecommons.org/licenses/by-nc-nd/4.0/.

\section{References}

1. Lambert AW, Pattabiraman DR, Weinberg RA. Emerging Biological Principles of Metastasis. Cell 2017;168:670-91.

2. de Boer M, van Dijck JA, Bult P, et al. Breast cancer prognosis and occult lymph node metastases, isolated tumor cells, and micrometastases. J Natl Cancer Inst 2010;102:410-25.

3. Zheng W, Aspelund A, Alitalo K. Lymphangiogenic factors, mechanisms, and applications. J Clin Invest 2014;124:878-87.

4. Banerji S, Ni J, Wang SX, et al. LYVE-1, a new homologue of the CD44 glycoprotein, is a lymph-specific receptor for hyaluronan. J Cell Biol 1999;144:789-801.

5. Wigle JT, Oliver G. Prox 1 function is required for the development of the murine lymphatic system. Cell 1999;98:769-78.

6. Zawieja DC. Contractile physiology of lymphatics. Lymphat Res Biol 2009;7:87-96.

7. Hos D, Schlereth SL, Bock F, et al. Antilymphangiogenic therapy to promote transplant survival and to reduce cancer metastasis: what can we learn from the eye? Semin Cell Dev Biol 2015;38:117-30.

8. Lee HW, Yu P, Simons M. Recent advances in understanding lymphangiogenesis and metabolism. F1000Res 2018;7:F1000 Faculty Rev-1114.

9. Yamakawa M, Doh SJ, Santosa SM, et al. Potential lymphangiogenesis therapies: Learning from current antiangiogenesis therapies-A review. Med Res Rev 2018;38:1769-98.

10. Friedl P, Alexander S. Cancer invasion and the microenvironment: plasticity and reciprocity. Cell 2011;147:992-1009.

11. Jung HY, Fattet L, Yang J. Molecular pathways: linking tumor microenvironment to epithelial-mesenchymal transition in metastasis. Clin Cancer Res 2015;21:962-8.

12. Paget $\mathrm{S}$. The distribution of secondary growths in cancer of the breast. 1889. Cancer Metastasis Rev 1989;8:98-101.

13. Greene HS, Harvey EK. The Relationship between the Dissemination of Tumor Cells and the Distribution of Metastases. Cancer Res 1964;24:799-811.

14. Schackert G, Fidler IJ. Site-specific metastasis of mouse melanomas and a fibrosarcoma in the brain or meninges of syngeneic animals. Cancer Res 1988;48:3478-84.

15. Jayson GC, Kohn EC, Kitchener HC, et al. Ovarian cancer. Lancet 2014;384:1376-88.

16. Joyce JA, Pollard JW. Microenvironmental regulation of metastasis. Nat Rev Cancer 2009;9:239-52.

17. Liotta LA, Kohn EC. The microenvironment of the tumour-host interface. Nature 2001;411:375-9.

18. Reich O, Regauer S, Marth C, et al. Precancerous Lesions of the Cervix, Vulva and Vagina According to the 2014 WHO Classification of Tumors of the Female Genital Tract. Geburtshilfe Frauenheilkd 2015;75:1018-20.

19. Karaman S, Detmar M. Mechanisms of lymphatic metastasis. J Clin Invest 2014;124:922-8.

20. Karst AM, Levanon K, Drapkin R. Modeling high-grade serous ovarian carcinogenesis from the fallopian tube. Proc Natl Acad Sci U S A 2011;108:7547-52.

21. Wiegand KC, Shah SP, Al-Agha OM, et al. ARID1A mutations in endometriosis-associated ovarian carcinomas. N Engl J Med 2010;363:1532-43.

22. Varghese A, Shih IM. Not All Peritoneal Implants Are Created Equal. Gynecol Oncol 2020;156:1-2.

23. Talmadge JE, Fidler IJ. AACR centennial series: the biology of cancer metastasis: historical perspective. Cancer Res 2010;70:5649-69.

24. Moore JE Jr, Bertram CD. Lymphatic System Flows. Annu Rev Fluid Mech 2018;50:459-82.

25. Oliver G. Lymphatic vasculature development. Nat Rev Immunol 2004;4:35-45.

26. Tucker WD, Arora Y, Mahajan K. Anatomy, Blood Vessels. In: StatPearls [Internet]. Treasure Island (FL): StatPearls Publishing; 2020.

27. Oliver G, Alitalo K. The lymphatic vasculature: recent progress and paradigms. Annu Rev Cell Dev Biol 2005;21:457-83.

28. Kawai Y, Ohhashi T. Topics of physiological and pathophysiological functions of lymphatics. Curr Mol Med 2009;9:942-53.

29. Huntington GS MC. The anatomy and development of the jugular lymph sacs in the domestic cat (Felis domestica). Anat Rec 1908;2:1-18.

30. Sabin FR. On the origin of the lymphatic system from the veins and the development of the lymph hearts and thoracic duct in the pig. Am J Anat 1902;1:367-89.

31. Mandriota SJ, Jussila L, Jeltsch M, et al. Vascular endothelial growth factor-C-mediated lymphangiogenesis promotes tumour metastasis. EMBO J 2001;20:672-82.

32. Skobe $M$, Hawighorst T, Jackson DG, et al. Induction of tumor lymphangiogenesis by VEGF-C promotes breast cancer metastasis. Nat Med 2001;7:192-8.

33. Achen MG, Jeltsch M, Kukk E, et al. Vascular endothelial 
growth factor D (VEGF-D) is a ligand for the tyrosine kinases VEGF receptor 2 (Flk1) and VEGF receptor 3 (Flt4). Proc Natl Acad Sci U S A 1998;95:548-53.

34. Breiteneder-Geleff S, Soleiman A, Kowalski H, et al. Angiosarcomas express mixed endothelial phenotypes of blood and lymphatic capillaries: podoplanin as a specific marker for lymphatic endothelium. Am J Pathol 1999;154:385-94.

35. Schacht V, Dadras SS, Johnson LA, et al. Up-regulation of the lymphatic marker podoplanin, a mucin-type transmembrane glycoprotein, in human squamous cell carcinomas and germ cell tumors. Am J Pathol 2005;166:913-21.

36. Paavonen K, Horelli-Kuitunen N, Chilov D, et al. Novel human vascular endothelial growth factor genes VEGF-B and VEGF-C localize to chromosomes 11q13 and 4q34, respectively. Circulation 1996;93:1079-82.

37. Laakkonen P, Porkka K, Hoffman JA, et al. A tumorhoming peptide with a targeting specificity related to lymphatic vessels. Nat Med 2002;8:751-5.

38. Alitalo K, Carmeliet P. Molecular mechanisms of lymphangiogenesis in health and disease. Cancer Cell 2002;1:219-27.

39. Wigle JT, Harvey N, Detmar M, et al. An essential role for Prox1 in the induction of the lymphatic endothelial cell phenotype. EMBO J 2002;21:1505-13.

40. Black SA, Nelson AC, Gurule NJ, et al. Semaphorin 7 a exerts pleiotropic effects to promote breast tumor progression. Oncogene 2016;35:5170-8.

41. Ji H, Cao R, Yang Y, et al. TNFR1 mediates TNF-alphainduced tumour lymphangiogenesis and metastasis by modulating VEGF-C-VEGFR3 signalling. Nat Commun 2014;5:4944.

42. Baggiolini M. Chemokines and leukocyte traffic. Nature 1998;392:565-8.

43. Buttler K, Kreysing A, von Kaisenberg CS, et al. Mesenchymal cells with leukocyte and lymphendothelial characteristics in murine embryos. Dev Dyn 2006;235:1554-62.

44. Karkkainen MJ, Haiko P, Sainio K, et al. Vascular endothelial growth factor $\mathrm{C}$ is required for sprouting of the first lymphatic vessels from embryonic veins. Nat Immunol 2004;5:74-80.

45. Sweat RS, Sloas DC, Murfee WL. VEGF-C induces lymphangiogenesis and angiogenesis in the rat mesentery culture model. Microcirculation 2014;21:532-40.

46. Fatima A, Wang Y, Uchida Y, et al. Foxc1 and Foxc2 deletion causes abnormal lymphangiogenesis and correlates with ERK hyperactivation. J Clin Invest 2016; 126:2437-51.

47. Ou JJ, Wei X, Peng Y, et al. Neuropilin-2 mediates lymphangiogenesis of colorectal carcinoma via a VEGFC/VEGFR3 independent signaling. Cancer Lett 2015;358:200-9.

48. Yan ZX, Jiang ZH, Liu NF. Angiopoietin-2 promotes inflammatory lymphangiogenesis and its effect can be blocked by the specific inhibitor L1-10. Am J Physiol Heart Circ Physiol 2012;302:H215-23.

49. Wang Y, Nakayama M, Pitulescu ME, et al. Ephrin-B2 controls VEGF-induced angiogenesis and lymphangiogenesis. Nature 2010;465:483-6.

50. Christiansen A, Detmar M. Lymphangiogenesis and cancer. Genes Cancer 2011;2:1146-58.

51. Podgrabinska S, Skobe M. Role of lymphatic vasculature in regional and distant metastases. Microvasc Res 2014; 95:46-52.

52. Jain RK, Fenton BT. Intratumoral lymphatic vessels: a case of mistaken identity or malfunction? J Natl Cancer Inst 2002;94:417-21.

53. Carr I. Lymphatic metastasis. Cancer Metastasis Rev 1983;2:307-17.

54. Jain RK, Munn LL, Fukumura D. Dissecting tumour pathophysiology using intravital microscopy. Nat Rev Cancer 2002;2:266-76.

55. Yancopoulos GD, Davis S, Gale NW, et al. Vascularspecific growth factors and blood vessel formation. Nature 2000;407:242-8.

56. Fisher B, Fisher ER. The interrelationship of hematogenous and lymphatic tumor cell dissemination. Surg Gynecol Obstet 1966;122:791-8.

57. Weiss L, Schmid-Schonbein GW. Biomechanical interactions of cancer cells with the microvasculature during metastasis. Cell Biophys 1989;14:187-215.

58. Weiss L. The pathobiology of metastasis within the lymphatic system. Surg Oncol Clin N Am 1996;5:15-24.

59. Hong MK, Macintyre G, Wedge DC, et al. Tracking the origins and drivers of subclonal metastatic expansion in prostate cancer. Nat Commun 2015;6:6605.

60. Macintyre G, Van Loo P, Corcoran NM, et al. How Subclonal Modeling Is Changing the Metastatic Paradigm. Clin Cancer Res 2017;23:630-5.

61. Stacker SA, Williams SP, Karnezis T, et al. Lymphangiogenesis and lymphatic vessel remodelling in cancer. Nat Rev Cancer 2014;14:159-72.

62. Brown M, Assen FP, Leithner A, et al. Lymph node blood vessels provide exit routes for metastatic tumor cell 
dissemination in mice. Science 2018;359:1408-11.

63. Werner-Klein M, Scheitler S, Hoffmann M, et al. Genetic alterations driving metastatic colony formation are acquired outside of the primary tumour in melanoma. Nat Commun 2018;9:595.

64. Jones D, Pereira ER, Padera TP. Growth and Immune Evasion of Lymph Node Metastasis. Front Oncol 2018;8:36.

65. Faries MB, Thompson JF, Cochran AJ, et al. Completion Dissection or Observation for Sentinel-Node Metastasis in Melanoma. N Engl J Med 2017;376:2211-22.

66. Naxerova K, Reiter JG, Brachtel E, et al. Origins of lymphatic and distant metastases in human colorectal cancer. Science 2017;357:55-60.

67. Wright JD, Huang Y, Burke WM, et al. Influence of Lymphadenectomy on Survival for Early-Stage Endometrial Cancer. Obstet Gynecol 2016;127:109-18.

68. Martinez-Corral I, Ulvmar MH, Stanczuk L, et al. Nonvenous origin of dermal lymphatic vasculature. Circ Res 2015;116:1649-54.

69. Kesler CT, Pereira ER, Cui CH, et al. Angiopoietin-4 increases permeability of blood vessels and promotes lymphatic dilation. FASEB J 2015;29:3668-77.

70. Jeltsch M, Kaipainen A, Joukov V, et al. Hyperplasia of lymphatic vessels in VEGF-C transgenic mice. Science 1997;276:1423-5.

71. Oh SJ, Jeltsch MM, Birkenhager R, et al. VEGF and VEGF-C: specific induction of angiogenesis and lymphangiogenesis in the differentiated avian chorioallantoic membrane. Dev Biol 1997;188:96-109.

72. Joukov V, Sorsa T, Kumar V, et al. Proteolytic processing regulates receptor specificity and activity of VEGF-C. EMBO J 1997;16:3898-911.

73. Hoshida T, Isaka N, Hagendoorn J, et al. Imaging steps of lymphatic metastasis reveals that vascular endothelial growth factor-C increases metastasis by increasing delivery of cancer cells to lymph nodes: therapeutic implications. Cancer Res 2006;66:8065-75.

74. Zhang YQ, Chen WL, Zhang F, et al. Over-expression of both VEGF-C and Twist predicts poor prognosis in human breast cancer. Clin Transl Oncol 2019;21:1250-9.

75. Szajewski M, Kruszewski WJ, Lakomy J, et al. VEGF-C and VEGF-D overexpression is more common in leftsided and well-differentiated colon adenocarcinoma. Oncol Rep 2014;31:125-30.

76. Bi MM, Shang B, Wang Z, et al. Expression of CXCR4 and VEGF-C is correlated with lymph node metastasis in non-small cell lung cancer. Thorac Cancer 2017;8:634-41.
77. Oplawski M, Dziobek K, Zmarzly N, et al. Expression Profile of VEGF-C, VEGF-D, and VEGFR-3 in Different Grades of Endometrial Cancer. Curr Pharm Biotechnol 2019;20:1004-10.

78. Huang YW, Xu LQ, Luo RZ, et al. VEGF-c expression in an in vivo model of orthotopic endometrial cancer and retroperitoneal lymph node metastasis. Reprod Biol Endocrinol 2013;11:49.

79. Kuerti S, Oliveira-Ferrer L, Milde-Langosch K, et al. VEGF-C expression attributes the risk for lymphatic metastases to ovarian cancer patients. Oncotarget 2017;8:43218-27.

80. Jach R, Dyduch G, Radon-Pokracka M, et al. Expression of vascular endothelial growth factors VEGF-C and D, VEGFR-3, and comparison of lymphatic vessels density labeled with D2-40 antibodies as a prognostic factors in vulvar intraepithelial neoplasia (VIN) and invasive vulvar cancer. Neuro Endocrinol Lett 2011;32:530-9.

81. Dai Y, Tong R, Guo H, et al. Association of CXCR4, CCR7, VEGF-C and VEGF-D expression with lymph node metastasis in patients with cervical cancer. Eur J Obstet Gynecol Reprod Biol 2017;214:178-83.

82. Springer TA. Traffic signals for lymphocyte recirculation and leukocyte emigration: the multistep paradigm. Cell 1994;76:301-14.

83. Miller MJ, Wei SH, Parker I, et al. Two-photon imaging of lymphocyte motility and antigen response in intact lymph node. Science 2002;296:1869-73.

84. Gunn MD, Kyuwa S, Tam C, et al. Mice lacking expression of secondary lymphoid organ chemokine have defects in lymphocyte homing and dendritic cell localization. J Exp Med 1999;189:451-60.

85. Kalliolias GD, Ivashkiv LB. TNF biology, pathogenic mechanisms and emerging therapeutic strategies. Nat Rev Rheumatol 2016;12:49-62.

86. Cao R, Ji H, Feng N, et al. Collaborative interplay between FGF-2 and VEGF-C promotes lymphangiogenesis and metastasis. Proc Natl Acad Sci U S A 2012;109:15894-9.

87. Fagiani E, Lorentz P, Kopfstein L, et al. Angiopoietin-1 and -2 exert antagonistic functions in tumor angiogenesis, yet both induce lymphangiogenesis. Cancer Res 2011;71:5717-27.

88. Cao R, Bjorndahl MA, Religa P, et al. PDGF-BB induces intratumoral lymphangiogenesis and promotes lymphatic metastasis. Cancer Cell 2004;6:333-45.

89. Hla T, Neilson K. Human cyclooxygenase-2 cDNA. Proc Natl Acad Sci U S A 1992;89:7384-8.

90. Elder AM, Tamburini BAJ, Crump LS, et al. 
Semaphorin 7A Promotes Macrophage-Mediated Lymphatic Remodeling during Postpartum Mammary Gland Involution and in Breast Cancer. Cancer Res 2018;78:6473-85.

91. Lund AW, Duraes FV, Hirosue S, et al. VEGF-C promotes immune tolerance in B16 melanomas and crosspresentation of tumor antigen by lymph node lymphatics. Cell Rep 2012;1:191-9.

92. Gonzalez H, Robles I, Werb Z. Innate and acquired immune surveillance in the postdissemination phase of metastasis. FEBS J 2018;285:654-64.

93. Fankhauser M, Broggi MAS, Potin L, et al. Tumor lymphangiogenesis promotes $\mathrm{T}$ cell infiltration and potentiates immunotherapy in melanoma. Sci Transl Med 2017;9:eaal4712.

94. Olszewski WL. The innate reaction of the human skin lymphatic system to foreign and self-antigens. Lymphat Res Biol 2005;3:50-7.

95. Randolph GJ, Angeli V, Swartz MA. Dendritic-cell trafficking to lymph nodes through lymphatic vessels. Nat Rev Immunol 2005;5:617-28.

96. Card CM, Yu SS, Swartz MA. Emerging roles of lymphatic endothelium in regulating adaptive immunity. J Clin Invest 2014;124:943-52.

97. Garnier L, Gkountidi AO, Hugues S. Tumor-Associated Lymphatic Vessel Features and Immunomodulatory Functions. Front Immunol 2019;10:720.

98. Tewalt EF, Cohen JN, Rouhani SJ, et al. Lymphatic endothelial cells induce tolerance via PD-L1 and lack of costimulation leading to high-level PD-1 expression on CD8 T cells. Blood 2012;120:4772-82.

99. Cohen JN, Guidi CJ, Tewalt EF, et al. Lymph noderesident lymphatic endothelial cells mediate peripheral tolerance via Aire-independent direct antigen presentation. J Exp Med 2010;207:681-8.

100.Lukacs-Kornek V, Malhotra D, Fletcher AL, et al. Regulated release of nitric oxide by nonhematopoietic stroma controls expansion of the activated $\mathrm{T}$ cell pool in lymph nodes. Nat Immunol 2011;12:1096-104.

Cite this article as: Matanes E, Gotlieb WH. Pathophysiological and anatomical basis of lymphatic transit of cancer cells and role of the lymphatic system: a review of published literature. Chin Clin Oncol 2021;10(2):14. doi: 10.21037/cco-20-205
101.Podgrabinska S, Kamalu O, Mayer L, et al. Inflamed lymphatic endothelium suppresses dendritic cell maturation and function via Mac-1/ICAM-1-dependent mechanism. J Immunol 2009;183:1767-79.

102. Tokumoto $M$, Tanaka H, Tauchi $Y$, et al. Immunoregulatory Function of Lymphatic Endothelial Cells in Tumor-draining Lymph Nodes of Human Gastric Cancer. Anticancer Res 2017;37:2875-83.

103. Rouhani SJ, Eccles JD, Riccardi P, et al. Roles of lymphatic endothelial cells expressing peripheral tissue antigens in CD4 T-cell tolerance induction. Nat Commun 2015;6:6771.

104. Dubrot J, Duraes FV, Potin L, et al. Lymph node stromal cells acquire peptide-MHCII complexes from dendritic cells and induce antigen-specific CD4(+) T cell tolerance. J Exp Med 2014;211:1153-66.

105. Grigorova IL, Schwab SR, Phan TG, et al. Cortical sinus probing, S1P1-dependent entry and flow-based capture of egressing T cells. Nat Immunol 2009;10:58-65.

106. Mendoza A, Fang V, Chen C, et al. Lymphatic endothelial $\mathrm{S} 1 \mathrm{P}$ promotes mitochondrial function and survival in naive T cells. Nature 2017;546:158-61.

107.Lund AW, Medler TR, Leachman SA, et al. Lymphatic Vessels, Inflammation, and Immunity in Skin Cancer. Cancer Discov 2016;6:22-35.

108. Yeo KP, Angeli V. Bidirectional Crosstalk between Lymphatic Endothelial Cell and T Cell and Its Implications in Tumor Immunity. Front Immunol 2017;8:83.

109. Kimura T, Sugaya M, Oka T, et al. Lymphatic dysfunction attenuates tumor immunity through impaired antigen presentation. Oncotarget 2015;6:18081-93.

110.Song E, Mao T, Dong H, et al. VEGF-C-driven lymphatic drainage enables immunosurveillance of brain tumours. Nature 2020;577:689-94.

111. Mlecnik B, Bindea G, Kirilovsky A, et al. The tumor microenvironment and Immunoscore are critical determinants of dissemination to distant metastasis. Sci Transl Med 2016;8:327ra26. 